\title{
EDITORIAL
}

\section{O PASTICHE, A CIÊNCIA BRASILEIRA E O POEMA DE MANUEL BANDEIRA}

A Revista Entre-Lugar apresenta seu segundo número de 2021, sua vigésima quarta edição. Como nas outras edições a publicação deste número é resultado do empenho dos pareceristas, dos autores e do apoio técnico recebido da Editora da UFGD, a qual tem dedicado esforços para manter a qualidade e o funcionamento do portal de periódicos, mesmo frente a tantas adversidades registradas no ano de 2021.

O trabalho conjunto é uma marca importante da REL (Revista Entre-Lugar), ele permite dar continuidade aquilo pensado no passado quando da criação da revista e a publicação das edições semestrais. A elaboração da capa desta edição contou com o apoio de técnico Rafael Brugnolli Medeiros, egresso do PPGG-UFGD. A doutoranda Lidiane Perbelin Rodrigues se encarregou da revisão técnica dos artigos, isso no que se refere ao atendimento das normas. Agradecemos imediatamente ambos pelo trabalho realizado.

Sobre a capa desta edição. As figuras dos textos foram usadas como hachuras a fim de preencher o Entre-Lugar sempre presente no logotipo da revista. Não há uma exatidão métrica, prevalece a ideia do preenchimento do Entre-Lugar, o qual, como na realidade, não corresponde necessariamente há representações fixas. O leitor e os próprios autores deverão buscar nas figuras o significado geográfico do onde e seus por quês. A palavra pastiche aqui ganha o contexto presente nas artes plásticas, se mescla ao autor do poema que fecha esse editorial, usuário habitual dessa técnica.

O tempo pró-tempore e pandêmico, sobrecarregado e incerto, relatado no editorial da vigésima terceira edição, não se diluiu; registramos ainda a permanência de uma necropolítica e o desmantelamento daquilo que sustenta e/ou sustentava a universidade pública e a pesquisa científica brasileira.. As estruturas normativas, o fomento financeiro, o regramento, os princípios políticos e administrativos construídos e consolidados por décadas a partir de esforços individuais e coletivos cada vez se tornam mais frágeis e distantes do ideal. O contexto da pós-graduação brasileira se apresenta muito distante daquilo que foi vivenciado no período de 2000 a 2015 sob diversos aspectos, seja no que diz respeito ao financiamento e/ou regramentos normativos e/ou política institucional. O ano de 2021 é marcado assim por muitas 
manifestações, cartas de repúdio e ações colaborativas na internet a fim de denunciar e evitar de alguma forma o desmantelamento da ciência brasileira. A ANPEGE (Associação Nacional de Pós-Graduação e Pesquisa em Geografia) e a SBPC (Sociedade Brasileira para o Progresso da Ciência) se demonstraram ativas nesse processo.

O PNPG proposto o interstício 2011-2020 foi incorporado ao PNE (Plano Nacional de Educação) instituído pela Lei 13.005 de 2014, em suas vinte metas para educação brasileira vislumbrava-se aumentar "qualitativa e quantitativamente o desempenho científico tecnológico do país e a competitividade internacional da pesquisa brasileira", e, "ampliar o investimento na formação de doutores de modo a atingir a proporção de 4 (quatro) doutores por 1.000 (mil) habitantes", ao contrário disto no presente observa-se um horizonte muito diferente.

A judicialização do processo de avaliação quadrienal da CAPES, os pedidos de renúncias nos comitês de áreas e o atraso na formulação do PNPG (Planos Nacionais de PósGraduação) para o período 2021-2030 são fragmentos das incertezas que se apresentam e corroem diuturnamente o sistema de pós-graduação brasileiro, e, por consequência, a formação de recursos humanos especializados, a pesquisa científica e o desenvolvimento de Ciência \& Tecnologia. Esse panorama foi retratado na Revista Pesquisa Fapesp, Edição nº309 de novembro 2021, na reportagem "Turbulência no horizonte da pós-graduação", assinada por Fabricio Marques e disponível para leitura em: https://revistapesquisa.fapesp.br/folheie-aedicao-de-novembro-de-2021.

Soma-se. O que se apresentava como factual no âmbito do CNPq no que diz respeito a oferta de editais e possibilidades de financiamento à pesquisa nos parece um pastiche quando comparado aquilo ofertado a comunidade científica brasileira em anos anteriores. A palavra pastiche aqui ganha o tom negativo da manipulação desprovida de validade e credibilidade. $O$ corte imposto, a pedido do Ministério da Economia, a perda imediata de R \$ 600 milhões no orçamento da ciência brasileira surge assim como aquilo relatado na batalha de Batracomiomaquia, uma paródia cômica presente em poema épico. Batracomiomaquia retrata a caricatura posta no corte do orçamento previsto para a ciência brasileira, o ato em si e seu significado em curto prazo para a ciência brasileira é desastroso - uma busca pela palavra batracomiomaquia permitirá compreender o contexto de seu uso. Nem mesmo aquilo que se apresentava como um patrimônio da comunidade científica brasileira, reconhecida internacionalmente, a Plataforma Lattes, não passou ilesa em 2021. O mesmo aconteceu com a 
Plataforma Carlos Chagas. Ambas apresentaram problemas no decorrer do ano por falta de manutenção, prejudicando o cotidiano dos pesquisadores sob vários aspectos e formas.

Como aprendi nas minhas aulas de Geomorfologia Fluvial, um rio nunca se modifica abruptamente, raros são os casos; quase sempre são ações conjuntas, contínuas e interligadas que levam a sua modificação. A ação das ondas, por exemplo, em seu movimento contínuo e ininterrupto na base de suas margens leva ao solapamento, desencadeia movimentos de massa na forma de blocos, cuja consequência é a erosão e o assoreamento. O que se observou assim na CAPES e no CNPq no ano de 2021 foi o solapamento da estrutura que formam, que dão sustentação, ao desenvolvimento da Ciência \& Tecnologia do país - infelizmente. Daí a importância da Nota de Pesquisa, CNPq e a genealogia de um desmonte, escrita pela pesquisadora Denise Elias, nela encontraremos com objetividade, números e fatos sobre o quadro de fragilidade posto, o solapamento da ciência brasileira em curso.

O segundo número de 2021 da Revista Entre-Lugar apresenta aos seus leitores como sempre textos inéditos, decorrentes de experiências de pesquisa realizadas em diversas partes do Brasil. O texto de abertura é um registro especial, um fragmento da tese de doutorado de Alex Dias de Jesus, Redes da migração haitiana no Mato Grosso do Sul, agraciada pela CAPES como a melhor tese de Geografia no ano de 2021. Publicar o texto desse jovem pesquisador é um privilégio.

Os artigos que se seguem. A paisagem entre a região e o lugar explora campos da congruência semântica da categoria paisagem e seu diálogo com a região sob o aspecto teóricoconceitual, tendo como elemento de analise o movimento conhecido como virada cultural; faz reflexões sobre o uso do sentido da paisagem e sua construção nas formas discursivas.

O urbano no contexto acadêmico analisa o banco de dissertações do Programa de Pós-Graduação em Geografia da Universidade Federal do Piauí (PPGGEO-UFPI), o propósito, averiguar o estado da arte dos trabalhos voltados ao contexto da urbanização, evidenciando os procedimentos metodológicos utilizados nas pesquisas. Observa-se uma contribuição importante da pós-graduação em Geografia no que diz respeito ao estudo das cidades do Piauí - condição que reforça a importância dos programas de pós-graduação no âmbito da pesquisa brasileira. Essa importância também se faz presente no artigo Diagnóstico físico-ambiental da bacia hidrográfica do rio Santo Antônio, resultado de pesquisa realizada no Programa de Pós-Graduação em Geografia da UFGD, cujo objetivo foi analisar os componentes físicos e 
antrópicos dessa bacia hidrográfica de Mato Grosso do Sul fazendo uso de geoprocessamento e SIGs. Os resultados revelam a ocorrência de processos erosivos em função do uso e ocupação de áreas com restrições ao uso agrícola, uma condição que se repete com frequência no estado e sem trabalhos semelhantes não é possível a implementação de ações mitigadoras.

Geography, landscape and photogeography an experience in teaching deaf students aborda um tema desafiador, a inclusão de alunos com deficiência no processo de ensino-aprendizagem da Geografia. A proposta usa a geoiconográfica como instrumento, relata e analisa a experiência realizada com alunos surdos matriculados do $6^{\circ}$ ao $9^{\circ}$ ano do ensino fundamental de uma escola pública do Distrito Federal/Brasil. O foco, encontrar as relações e possibilidades de ensino-aprendizagem tendo como base três eixos: paisagem, fotogeografia e transdisciplinaridade. Observa-se a experiência sensitiva vivida durante atividade de campo, revela uma compreensão de mundo no a ausência parcial ou total do som cria outras dimensões, a espacialidade geográfica ganha uma outra estrutura lógica, registrada por meio de fotografias. Um texto singular e importante, acreditamos que sua publicação permitirá a realização de experiências semelhantes e ampliará o debate sobre a inclusão e a necessidade de uma Geografia inclusiva.

Para além dos artigos encaminhados em fluxo contínuo e selecionados para essa edição uma Seção Temática, "Técnicas Estatísticas e de Modelagem aplicadas à Climatologia”, se faz presente. A ST (Seção Temática) foi construída visando incentivar e promover à pesquisa científica no campo da Geografia. Elaborada a partir de uma ação colaborativa e interinstitucional a ST contou com um editor convidado, o Prof. Dr. Fabio de Oliveira Sanches, da Universidade Federal de Juiz de Fora. Uma experiência profícua cujo resultado inspira a realização de outras ST no futuro. O professor Fabio Sanches assina também o Editorial dessa edição.

Sobre a ST trazemos um conjunto de artigos que buscam demonstrar diversas técnicas estatísticas aplicadas aos estudos de climatologia desenvolvidos por geógrafos. O artigo intitulado Aplicação e avaliação de técnicas para o preenchimento de falhas de dados pluviométricos em anos habituais, secos e chuvosos traz a comparação de técnicas estatísticas para o preenchimento de falhas (regressão linear e ponderação regional) em dados pluviométricos mensais, bem como a aplicação de técnicas para avaliação da consistência dos valores preenchimentos (Coeficientes de Determinação, Correlação de Pearson, Teste Dupla- 
Massa, teste t de Student, Erro Médio Absoluto, Erro Relativo Médio e da Raiz do Erro Quadrado Médio), sobretudo para anos considerados, na Climatologia Geográfica, como habituais, secos e chuvosos.

\section{O artigo Validação estatística de dados do Tropical Rainfall Measuring Mission} (TRMM) para a bacia hidrográfica do rio Jordão - Paraná - Brasil nos apresenta uma alternativa para um antigo problema comumente enfrentado por climatologista/climatólogos, além das falhas de dados, a inexistência de estações meteorológicas em localidades de difícil acesso e/ou áreas remotas. Por meio dos recursos do satélite TRMM e de sua grade de dados, é demonstrado um método, e porque não também chamar de técnica, de ajuste e correção de seus dados à partir de dados obtidos em estações meteorológicas de superfície: a proposição de um modelo. Assim como o artigo sobre preenchimento de falhas, o qual abre essa ST, foram adotados procedimentos estatísticos que buscaram a validação e consistência dos dados obtidos.

Ambos os artigos demonstram o profundo cuidado e zelo com uma etapa extremamente importante em qualquer pesquisa em climatologia: a coleta, a organização $e$ preparação dos dados para análises posteriores.

No texto Dados discrepantes ou outliers: avaliação da quadra chuvosa do semiárido do RN, Brasil os leitores poderão encontrar técnicas qualitativas (Boxplot e Dotplots) e quantitativas (Escore Z, Escore Z Modificado, Grubbs e Dixon) para avaliar a ocorrência de dados discrepantes de precipitação no semiárido do estado do Rio Grande do Norte, considerando condições climáticas caracterizadas como habituais ou excepcionais.

Estudos sobre a região nordeste do Brasil são igualmente trazidos no artigo intitulado Análises estatísticas da precipitação e temperatura do ar em ambientes semiáridos. Nele, os autores exploram a adoção de técnicas da estatísticas descritiva (média, mediana, desvio padrão e anomalias) e inferencial ( $t$ de Student, Mann-Kendall e ANOVA) a fim de caracterizar diferenças em parte do semiárido nordestino.

Técnicas analisando as anomalias das chuvas e dos índices de seca meteorológica (Índice de Anomalia da Chuva, Índice Padronizado de Precipitação Modificado e decis), bem como análises de dispersão são desenvolvidos no artigo Climatologia do regime de chuvas em Campina Grande/PB: modelos e variabilidades. 
A avaliação de tendências também foi objeto de estudo em parte da região do Triângulo Mineiro, presente no texto Avaliação da tendência da precipitação no município de Campina Verde (MG) no período de 1976 a 2020. Nele os autores empregam a técnica consagrada em estudos sobre longas séries temporais na busca por evidências de mudanças no comportamento da pluviosidade, por meio de planilha eletrônica MAKESENS-application for trend calculation, disponível na web para pesquisadores que se debruçam sobre o tema.

Estudos sobre a climatologia na região Norte do Brasil são apresentados nos artigos Teleconexões atmosféricas e vazão fluvial na bacia amazônica brasileira por meio de mapas de correlação linear, e, Caracterização e variabilidade climática baseada em séries de temperatura e precipitação nos municípios de Manaus (AM) e Belém (PA). No primeiro, são demonstradas as correlações entre os padrões de teleconexões atmosféricas e as vazões dos rios da bacia amazônica por meio da aplicação de técnicas de análise de clusters e de coeficientes de correlação linear. No segundo artigo são aplicadas técnicas de estatística descritiva e modelagem polinomial para demonstrar e compreender as mudanças no comportamento das temperaturas e precipitações em Manaus e Belém, à partir da segunda metade do século XX.

Os dois últimos artigos da ST, mas não menos importantes, versam sobre estudos em Climatologia Urbana. O artigo Variação espaço-temporal da temperatura do ar no perímetro urbano de Ponte Nova, na Zona da Mata Mineira busca compreender as variações de temperatura na cidade de Ponte Nova (MG) analisando-os sob a perspectiva das diferenças e semelhanças estatísticas, técnicas dos quantis complementando suas análises por meio de técnicas como Sky View Factor e a participação das massas de ar no período de coleta dos dados. Por sua vez a Utilização do índice de área construída (IBI) para análise da evolução espaço-temporal da temperatura da superfície continental (TSC) na região metropolitana do rio de janeiro (RMRJ) nos traz o sensoriamento remoto como ferramenta de análise da atmosfera urbana, tendo como viés a compreensão da importância de averiguar as mudanças em sua superfície e suas correlações diretas e indiretas no clima urbano das cidades. Por meio do uso das imagens de satélite e seus recursos foi possível extrair um conjunto de índices e equações a partir de características físicas registradas pelos sensores remotos.

Para além do que já foi brevemente descrito sobre cada artigo da ST, cabe ressaltar, o caráter eminentemente didático apresentado nas técnicas estatísticas empregadas. Essa 
característica norteou a seleção dos artigos publicados, uma vez que essas e outras técnicas se mostram cada dia mais eficazes como ferramentas de análise para a Climatologia, sobretudo, para a Climatologia desenvolvida por geógrafos.

A ST trata-se, portanto, de uma contribuição aos estudos desenvolvidos por colegas da Geografia, pesquisadores da área da Climatologia, a qual tem ampliado, se apropriado do uso de ferramentas, de técnicas e de métodos da Estatística.

A edição termina com a resenha Um breve comentário a respeito do IPCC AR6, resultado da leitura e avaliação do Sexto Relatório de Avaliação (AR6) publicado pelo IPCC (Painel Intergovernamental sobre Mudanças Climáticas) em agosto de 2021. Como o próprio autor escreve "a publicação sintetiza o conhecimento sobre as bases físicas das ciências relacionadas ao clima, analisa as evidências científicas da mudança do clima tomando como parâmetro mais quatorze mil estudos". O relatório reforça tendências passadas, evidencia e não deixa dúvidas sobre qual o papel da sociedade no que tange a mudança do clima global, é enfático sobre a gravidade do problema.

Aqueles que chegaram até aqui, nossos agradecimentos. A mensagem permanece; que o conhecimento científico seja sempre aquele a descortinar o achismo e a ignorância, aquele a eliminar os dogmas e o fanatismo. Que a poesia, a literatura, a arte e outras formas de expressão nos ajudem a ir além da lógica e da racionalidade formal, para com isso sermos mais humanos - inclusive para compreendermos com clareza a importância e o papel social da Ciência. Cada vez mais isso nos parece essencial e reforça os princípios editoriais da REL.

Quando do término deste editorial a campainha soa, a cena cotidiana se repete, a pergunta se faz presente novamente: “Tem algo para dar?!”. Nesses tempos o pedido por comida é o mais comum. O flagelo que se abate sobre a comunidade indígena em Dourados é reconhecido nacionalmente, são eles os invisíveis, os transeuntes e os mais necessitados. Paradoxalmente na cidade cercada por commodity há fome, muita fome. O poema de Manuel Bandeira, "O Bicho", escrito em 1947, surge como um lampejo; passados setenta e quatro anos, em pleno século XXI, sua crítica social se apresenta como real e retrata fielmente aquilo que ainda presenciamos em Dourados e outras partes do Brasil nesse momento histórico marcado pela pandemia, arbitrariedades, fome e em certa medida a desesperança: 
Vi ontem um bicho

$\mathrm{Na}$ imundície do pátio

Catando comida entre os detritos.

Quando achava alguma coisa,

Não examinava nem cheirava:

Engolia com voracidade.

O bicho não era um cão,

Não era um gato,

Não era um rato.

O bicho, meu Deus, era um homem.

(Manuel Bandeira, “O Bicho”, 1947)

Que possamos incrementar, incentivar e fomentar o desejo por publicar, por se fazer ciência! Que possamos seguir acreditando em dias melhores! Em dias sem fome.

Charlei Aparecido da Silva

Editor da Revista Entre-Lugar

Bruno de Souza Lima

Secretário Executivo
Fabio de Oliveira Sanches

Editor da Seção Temática

Dourados (MS) - 2021

Final de Primavera, nunca é demais reafirmar aquilo que já foi dito:

"O pobre pode e deve comer camarão, ele tem o direito de ter o que produz." 